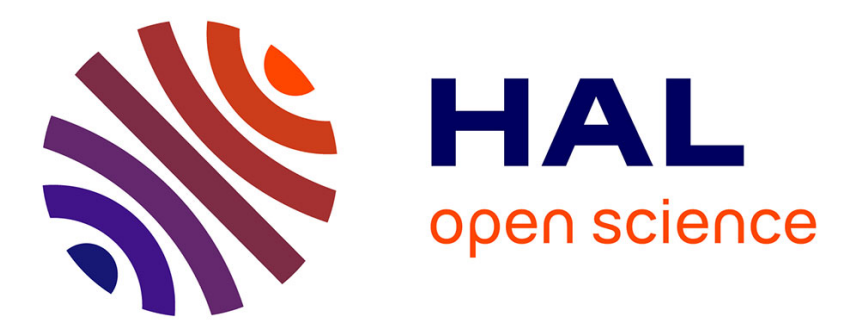

\title{
Forming limit curves in blow molding for polymers exhibiting deformation induced crystallization
}

\author{
Arnaud Poitou, Amine Ammar, Germaine Nefussi
}

\section{To cite this version:}

Arnaud Poitou, Amine Ammar, Germaine Nefussi. Forming limit curves in blow molding for polymers exhibiting deformation induced crystallization. International Journal of Forming Processing, 2002, 5 (2-3-4), pp.401-413. 10.3166/ijfp.5.413-421 . hal-01006906

\section{HAL Id: hal-01006906 https://hal.science/hal-01006906}

Submitted on 28 Feb 2017

HAL is a multi-disciplinary open access archive for the deposit and dissemination of scientific research documents, whether they are published or not. The documents may come from teaching and research institutions in France or abroad, or from public or private research centers.
L'archive ouverte pluridisciplinaire HAL, est destinée au dépôt et à la diffusion de documents scientifiques de niveau recherche, publiés ou non, émanant des établissements d'enseignement et de recherche français ou étrangers, des laboratoires publics ou privés.

\section{(c)(1)}

Distributed under a Creative Commons Attribution| 4.0 International License 


\section{Forming limit curves in blow molding for a polymer exhibiting deformation induced crystallization}

\section{Arnaud Poitou - Amine Ammar - Germaine Nefussi}

LMT - ENS de Cachan, 61 Avenue du président Wilson 94235 Cachan France poitou@Imt.ens-cachan.fr,ammar@lmt.ens-cachan.fr,nefussi@Imt.ens-cachan.fr

ABSTRACT: We address in this paper the problem of blow molding for a polymer exhibiting a deformation induced crystallization (e.g. Poly EthyleneTerephthalate or PET). In a first part, we give the equations of a model that couples the mechanics to the crystallization for a class of molecular models (e.g. Maxwell or POM-POM models). In a second part, without a real stabilities analysis, we follow the Swift analysis for biaxial deformations. We conclude this study in showing that it is possible to quantify how crystallization during the process stabilizes it. In enhancing strongly the strain hardening, crystallization is namely a stability factor against necking.

KEYWORDS: Quiescent and induced crystallization, blow molding, Considere criterion, necking. 


\section{Notations}

\begin{tabular}{|c|c|}
\hline$\underline{\underline{\mathrm{M}}}$ & tensorial notation $\left(\mathrm{M}_{\mathrm{ij}}\right)$ \\
\hline$\underline{\underline{\mathrm{M}}}: \underline{\underline{\mathrm{N}}}$ & $\operatorname{Tr}(\underline{\underline{M}} \cdot \underline{\underline{N}})=M_{i j} N_{i j}$ \\
\hline t & time \\
\hline $\mathrm{d} / \mathrm{dt}$ & time material derivative \\
\hline$\partial / \partial \mathrm{t}$ & time partial derivative \\
\hline$\delta / \delta \mathrm{t}$ & time upper convective derivative \\
\hline$\widetilde{D} / \widetilde{D} t$ & general notation for a convective derivative \\
\hline$X$ & thermodynamic internal variable \\
\hline$Y$ & thermodynamic dual variable \\
\hline$\phi$ & intrinsic dissipation \\
\hline$\psi$ & free energy \\
\hline$\rho_{0}$ & density \\
\hline$\underline{\tau}$ & extra stress tensor \\
\hline$\underline{\underline{D}}$ & strain rate tensor $\left(D_{i j}=\left(\mathrm{v}_{\mathrm{i}, \mathrm{j}}+\mathrm{v}_{\mathrm{j}, \mathrm{i}}\right) / 2\right)$ \\
\hline$n, \chi$ & kinetic parameters \\
\hline$T$ & temperature \\
\hline$\alpha$ & relative degree of crystallinity \\
\hline$f$ & intrinsic degree of crystallinity \\
\hline$\underline{\underline{Y}}$ & dual variable of elastic strain tensor \\
\hline$\eta$ & viscosity \\
\hline$\underline{v}$ & velocity field \\
\hline$G_{0}, \phi_{\mathrm{b}}$ & material parameter of the pompom model \\
\hline$\lambda$ & chain stretch \\
\hline$\underline{\underline{S}}$ & chain orientation tensor \\
\hline$\mu$ & dual variable of chain stretch \\
\hline$\underline{y}$ & dual variable of chain orientation tensor \\
\hline$\theta_{\mathrm{s}}$ & stretch relaxation time \\
\hline$\theta_{\mathrm{b}}$ & backbone relaxation time \\
\hline
\end{tabular}

\section{Introduction}

Blow molding is a process enabling to manufacture bottles. This process involves two steps. In a first step, a preform is injected molded and thus cooled quickly. For PET bottles this cooling time is too short to allow the material to crystallize. The preform is thus quite completely amorphous. In a second step the preform is heated, usually with infrared lights, at a temperature just above the glass temperature transition. The final shape of the bottle is then obtained with a combination of axial deformation and air blowing (figure 1). During this final stage, the material is subjected to very high deformation [1] and this deformation induces a crystallization, which varies form point to point with respect of the materials mechanical history (strain, strain rate, temperature ...). 

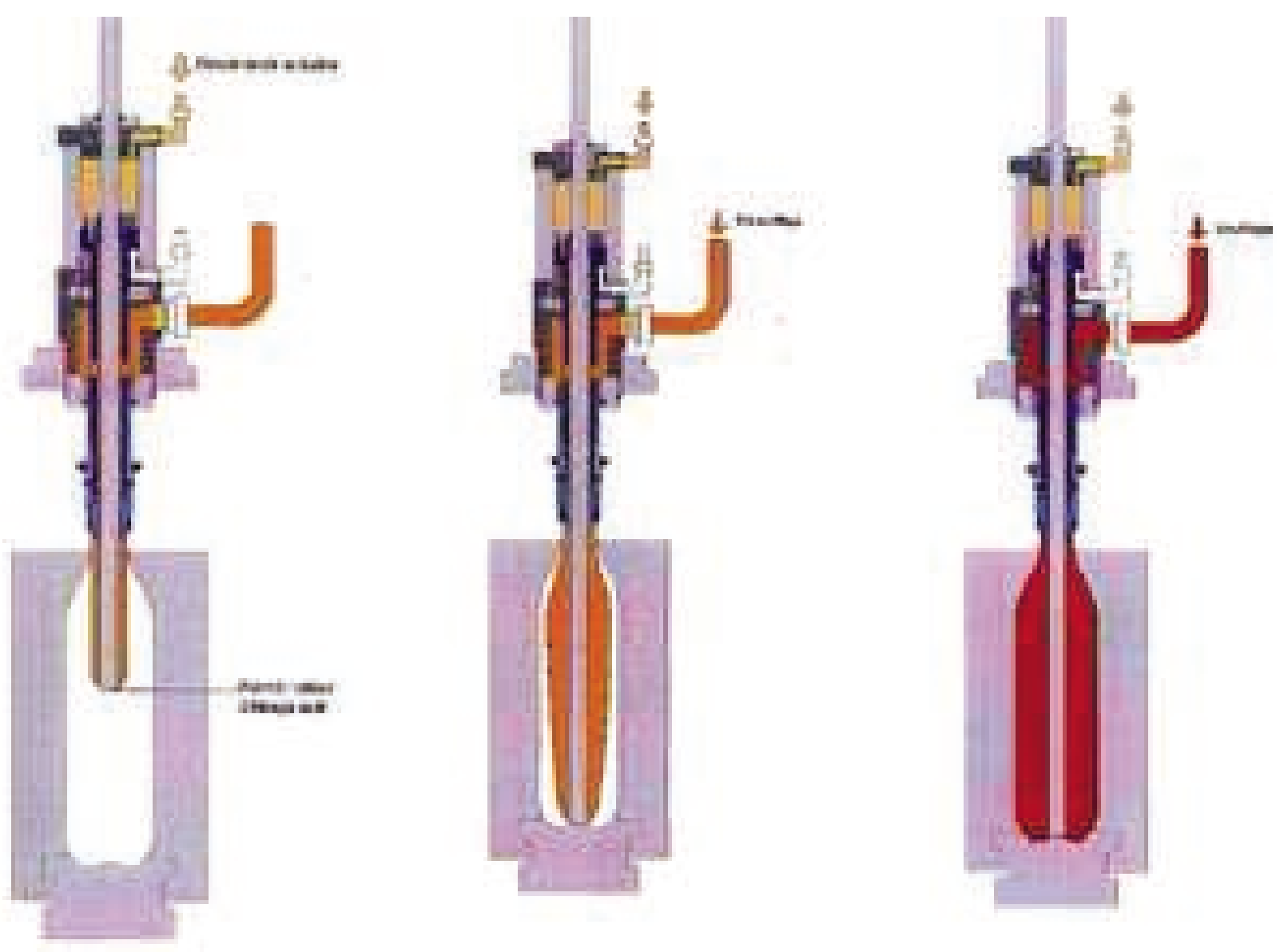

Figure 1. Blow molding process

The aim of this paper is not to propose a complete modeling of blow molding. We focus here on the flow induced crystallization phenomenon. In a first part we derive a framework for this modeling, which is illustrated here for a material whose constitutive relation is that of the Pom Pom model parameterized by the degree of crystallinity. In a second part, making a parallel between what is classically done for deep drawing, we analyze the occurrence of necking in terms of Considere and Swift Criterion.

\section{Equations}

Details of our model can be found in [2-4]. We give in the following the mathematical formulation of this model.

\subsection{Rheology}

The constitutive relation is chosen to be the Pom-Pom model, which exhibits two relaxation mechanisms: tube orientation $\underline{\underline{S}}$ and backbone stretch $\lambda$ (Figure 2). In its differential form, it can be written:

$$
\underline{\underline{\tau}}=\frac{15}{4} G_{0} \phi_{b}^{2} \lambda^{2} \underline{\underline{S}}
$$




$$
\begin{aligned}
& \frac{d \underline{\underline{S}}}{d t}= \underline{\underline{\operatorname{grad}}} \underline{\underline{\underline{S}}} \underline{\underline{\underline{S}}}+\underline{\underline{\underline{S}}} \cdot \underline{\underline{\operatorname{grad}} v_{T}}- \\
&-2(\underline{\underline{S}}: \underline{\underline{D}}) \underline{\underline{S}}-\frac{1}{\theta_{b}}\left(\underline{\underline{S}}-\frac{1}{3} \underline{\underline{ }}\right) \\
& \frac{d \lambda}{d t}=\lambda\left(\underline{\underline{\underline{S}}: \underline{\underline{D}})-\frac{1}{\theta_{s}}(\lambda-1)}\right.
\end{aligned}
$$

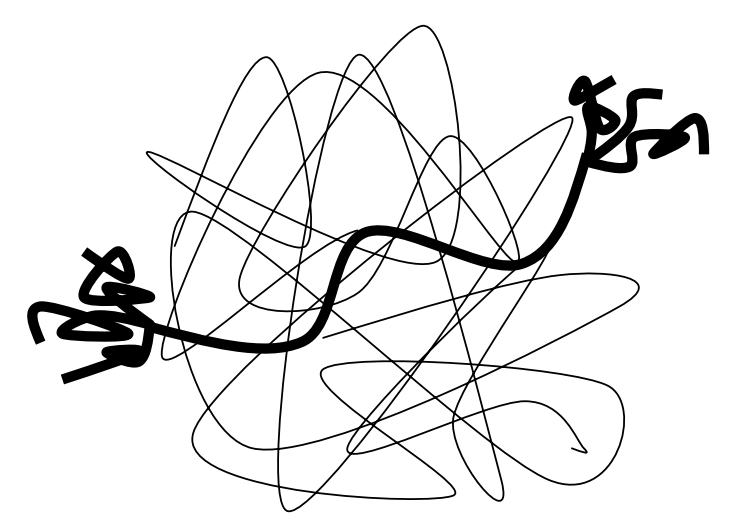

Figure 2. Branched polymer in a tube

\subsection{Quiescent crystallization}

Following Avrami model written in a differential form for non isothermal conditions, we assume that the relative degree of crystallinity $\alpha$ (ratio between the actual degree of crystallization and the ultimate or maximum degree of crystallization allowed by the polymer structure), in quiescent conditions (i.e. without any deformation of the material), increases with respect to time as:

$$
\left\{\begin{array}{l}
\alpha=1-\operatorname{Exp}(-f) \\
\frac{d f}{d t}=\frac{n \cdot f^{1-1 / n}}{\lambda(T)}
\end{array}\right.
$$

\subsection{Deformation induced crystallization}

In our formalism, strain (or flow) induced crystallization is directly deduced from equations [1-4]. If we assume indeed that the rheological parameters depend on the degree of crystallinity, a model of flow-induced crystallization is "naturally" associated to the rheology as soon as one writes the rheological model into a thermodynamical form. In our formalism, for the Pom Pom model, this strain induced crystallization model writes: 


$$
\begin{aligned}
\dot{f} & =\frac{\partial}{\partial \Lambda}\left(\frac{1}{\theta_{0}(\Lambda)}\right)\left(-\frac{H}{6} \operatorname{lndet} \frac{-2 y}{H}-\frac{1}{3} \operatorname{Tr}(\underline{y})-\frac{H}{2}\right) \\
& -\frac{\partial}{\partial \Lambda}\left(\frac{1}{\theta_{s}(\Lambda)}\right) \int_{0}^{\mu}\left(\frac{m}{H}-1+\sqrt{1+\left(\frac{m}{H}\right)_{2}}\right) d m \\
& +\frac{n}{\lambda(T)} f^{1-\frac{1}{n}} \\
H & =\frac{15}{4} G_{0} \phi_{b}^{2} \\
\underline{y} & =\frac{\partial \psi}{\partial \underline{S}}=-\frac{1}{6} H \underline{\underline{S}} \\
\mu & =\frac{\partial \psi}{\partial \lambda}=H\left(\lambda-\frac{1}{\lambda}\right) \\
\Lambda & =\frac{\partial \psi}{\partial f} \approx L x_{\infty}\left(1-\frac{T}{T_{m}}\right) \exp (-f)
\end{aligned}
$$

Equation [5] means that the crystallization is induced by three different sources. The last one is the classical thermal activation. The first one means that crystallization occurs as soon as (i) the molecules are oriented and (ii) the orientation relaxation time increases with respect to the degree of crystallinity. In a very similar way, the second term means that crystallization occurs as soon as (i) the molecules are stretched and (ii) the stretch relaxation time increases with respect to the degree of crystallinity. 


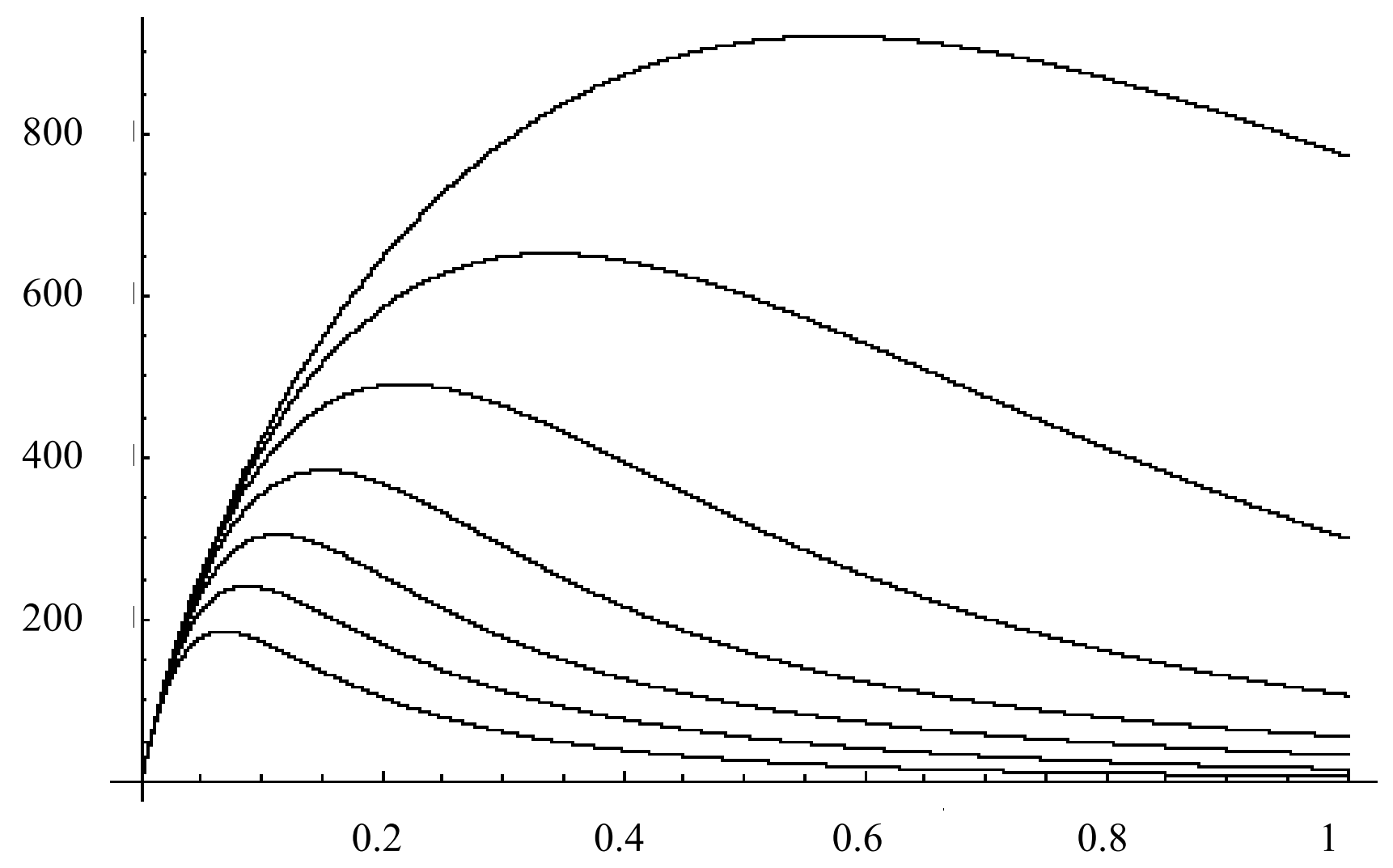

Figure 3. Tensile test for increasing tensile velocities, without strain induced crystallization (Relaxation times $\theta_{\mathrm{b}}=911 \mathrm{~s}, \theta_{\mathrm{s}}=150 \mathrm{~s}$, initial length $\mathrm{L}=0.1 \mathrm{~m}$, tensile velocity $\mathrm{V}=10^{-4}, 210^{-4}, 410^{-4}, 810^{-4}, 1.610^{-3,} 3.210^{-3}, 6.410^{-3} \mathrm{~m} / \mathrm{s}$ )

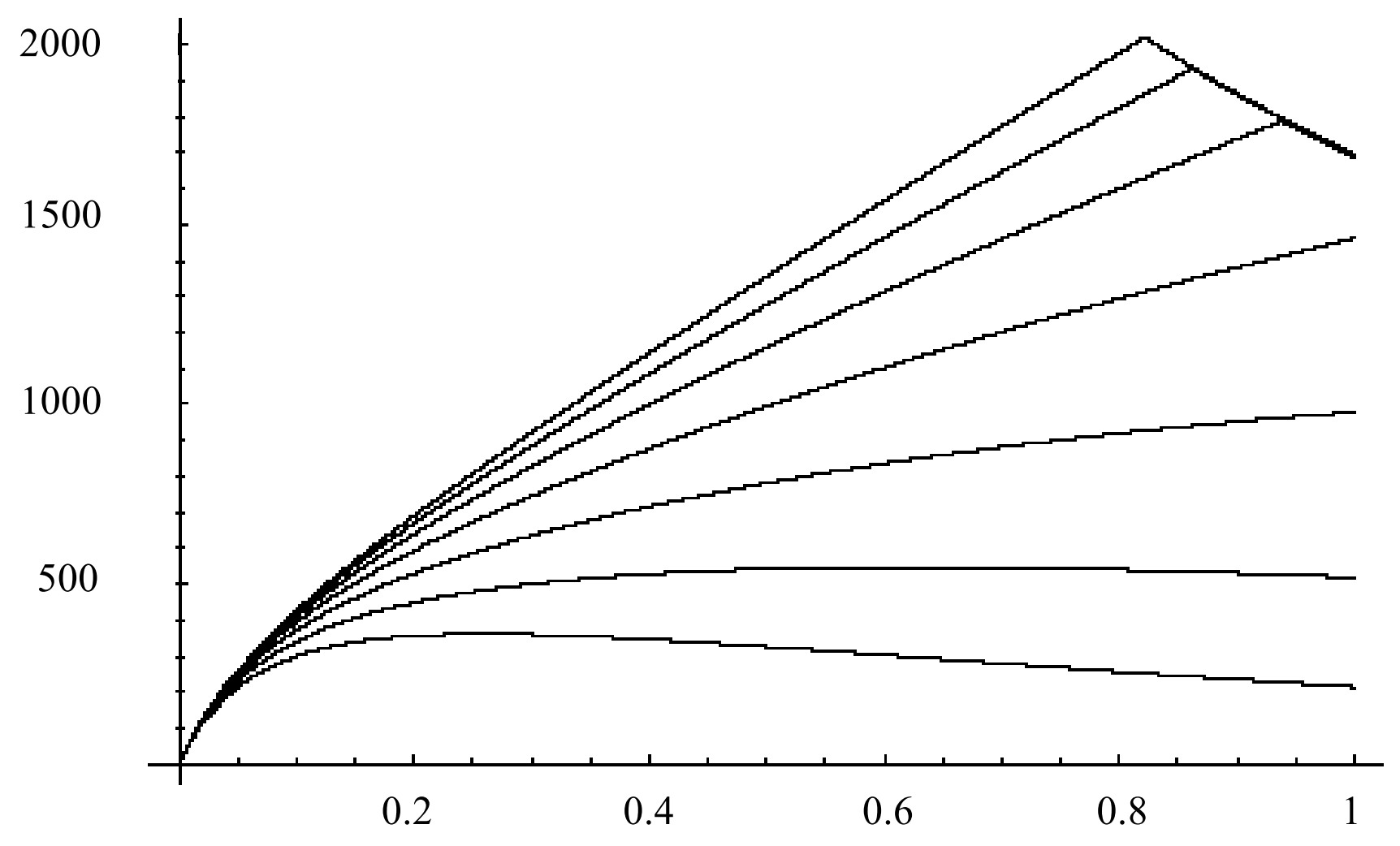

Figure 4. Tensile test for increasing tensile velocities,

for strong strain induced crystallization (Relaxation times $\theta_{\mathrm{b} 0}=911 \mathrm{~s}$, $\theta_{\mathrm{s} 0}=150 \mathrm{~s}, \theta_{\mathrm{b}}=\theta_{\mathrm{b} 0}(1+\mathrm{A} \alpha), \theta_{\mathrm{s}}=\theta_{\mathrm{s} 0}(1+\mathrm{A} \alpha), \mathrm{A}=100$, initial length $\mathrm{L}=0.1 \mathrm{~m}$, tensile velocity $\mathrm{V}=10^{-4}, 210^{-4}, 410^{-4}, 810^{-4}, 1.610^{-3}, 3.210^{-3}, 6.410^{-3} \mathrm{~m} / \mathrm{s}$ ) 


\section{Results and discussions}

\subsection{Tensile test}

A tensile test can be simulated in solving simultaneously equations [1-3] and [59] for a constant tensile velocity. Figure 3 shows a typical tensile curve without any strain-induced crystallization for increasing tensile velocities. The effect of velocity is classically to increase the force and to allow for a larger deformation without necking. Figure 4 shows the same tensile curves for the same rheological parameters but with strain induced crystallization. This situation evidences a strain hardening and a shift of the limit deformation before necking, that increase both with crystallization and strain rate. This strain hardening is effectively due to crystallization as can be seen on figure 5 , where are plotted the relative degree of crystallinity during the test.

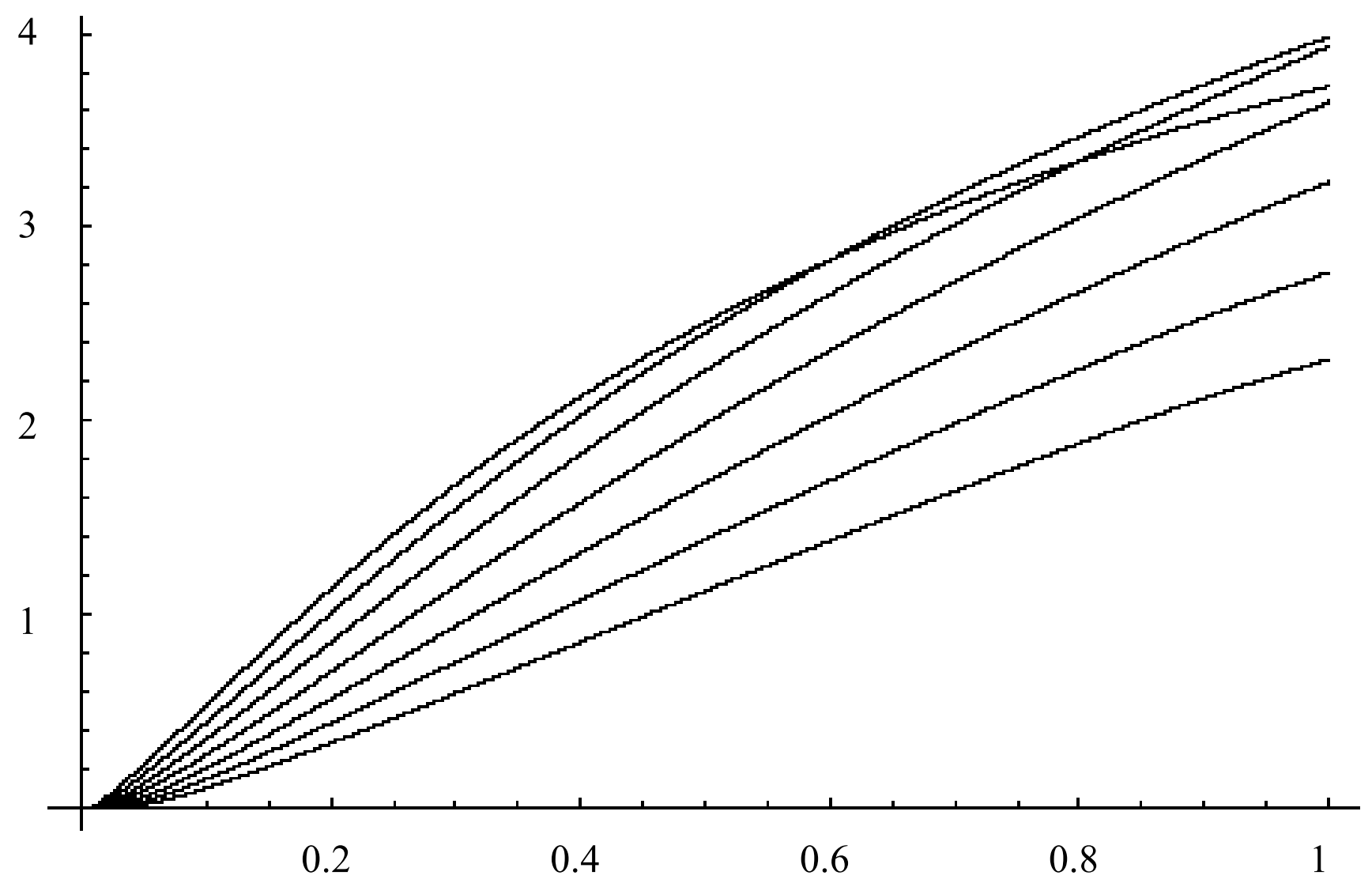

Figure 5. Relative degree of crystallinity during the tests illustrated in figure 4

\subsection{Bidimensionnal test}

In order to see the influence of bidimensionnal deformations, we have solved the equations for constant tensile velocities along two directions. We have then plotted the "limit curve" associated to the maximum of the force along one direction. Figures 6 and 7 show these limit curves for different velocities, without and with strain induced crystallization. In comparison with the Swift criterion, if we associate 
these limit curves to a forming limit curve, we see the positive role of crystallization, which acts as a necking stabilizer.

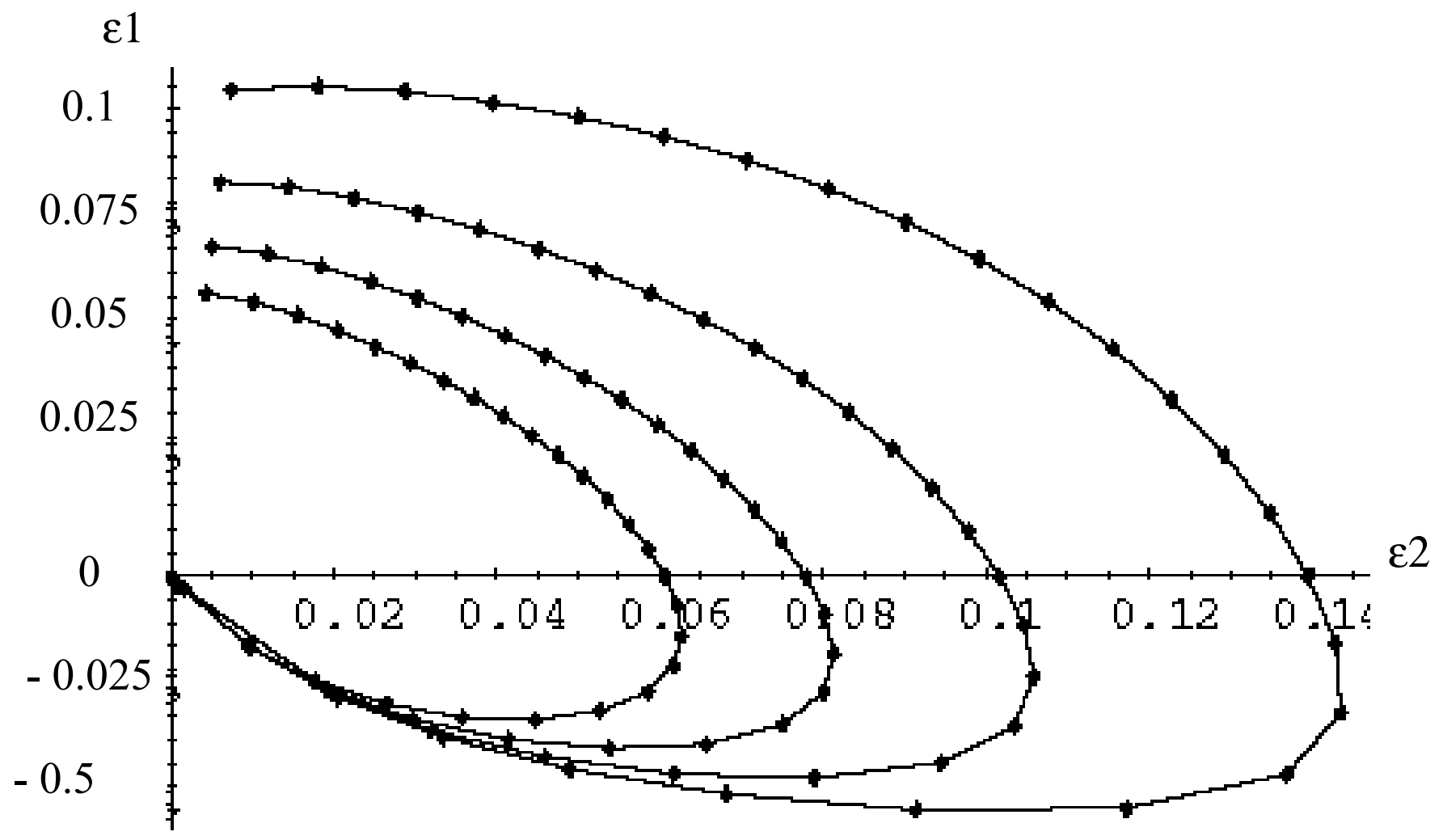

Figure 6. "Limit"curve without crystallization

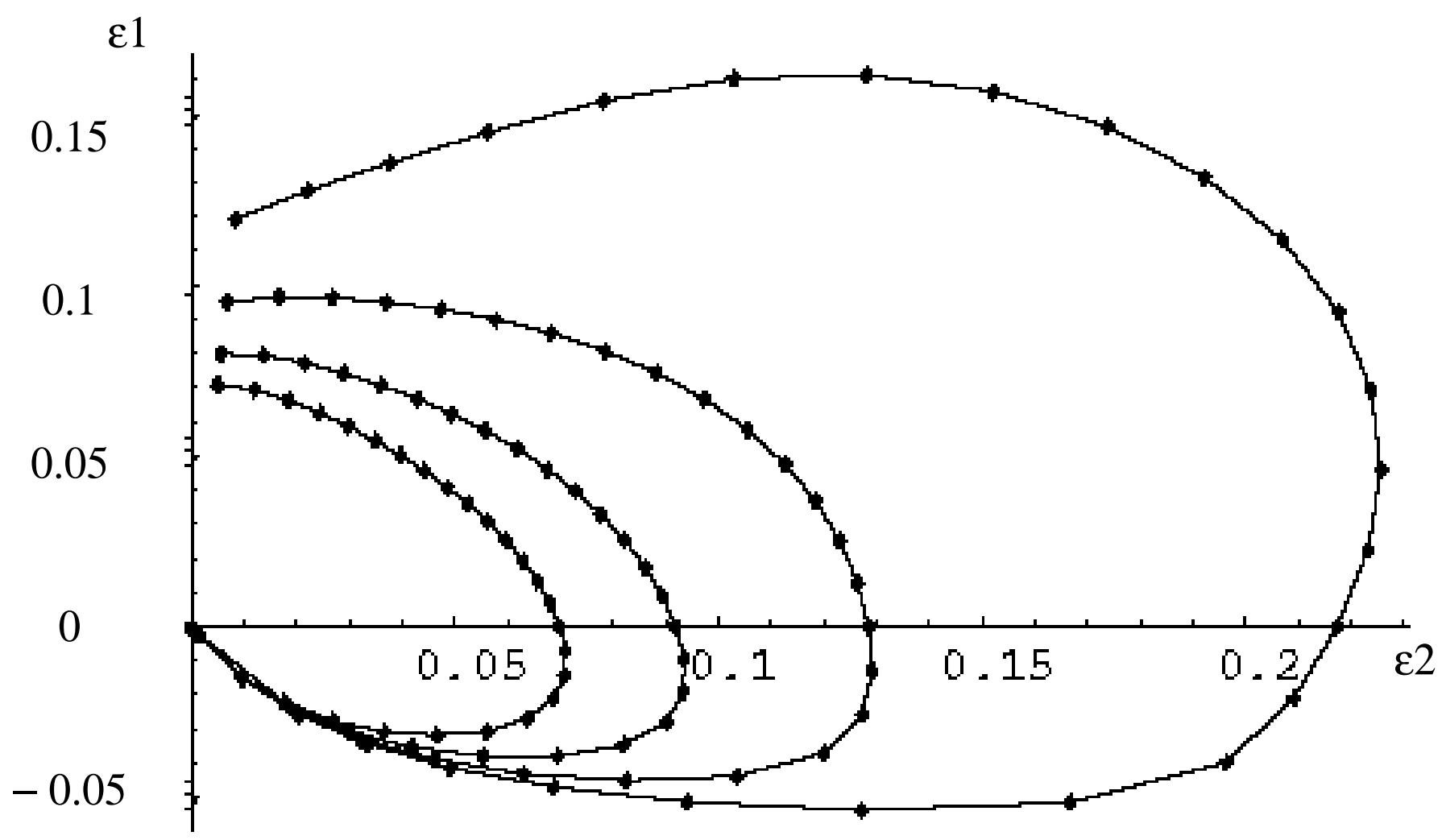

Figure 7. "Limit"curve with crystallization, (Relaxation times $\theta_{\mathrm{b} 0}=911 \mathrm{~s}$, 
$\theta_{\mathrm{s} 0}=150 \mathrm{~s}, \theta_{\mathrm{b}}=\theta_{\mathrm{b} 0}(1+\mathrm{A} \alpha), \theta_{\mathrm{s}}=\theta_{\mathrm{s} 0}(1+\mathrm{A} \alpha), \mathrm{A}=10$, initial length $\mathrm{L}=0.1 \mathrm{~m}$, tensile velocity $\mathrm{V}=10^{-4}, 210^{-4}, 410^{-4}, 810^{-4}, 1.610^{-3}, 3.210^{-3}, 6.410^{-3} \mathrm{~ms}^{-1}$ )

\section{Conclusion}

We have shown in this paper a model for flow-induced crystallization associated to a molecular model of the viscoelastic constitutive equation. This model is to be compared to McHugh one [5]. It allows us to describe both a strain hardening during plane deformation and qualitative forming limit curves in two dimensions that outline the stabilizing role of strain-induced crystallization. This model remains qualitative for blow molding because (i) it does not contain any yield stress (ii) a precise stability analysis has not been done yet. However these new development are not out of reach.

\section{References}

[1] L. Chevalier, C. Linhone, G. Regnier. « Induced crystallinity during stretch-blow molding process and its influence on mechanical strength of poly(ethylene terephthalate) bottles ». Plastic, Rubber and Composite. 1999, 28(8):385-392.

[2] A. Poitou, A. Ammar. "Polymer crystallization induced by flow : a thermodynamic approach ». C. R. Acad. Sci. 2001, 329(II b):5-11.

[3] A. Ammar. «Modélisation numérique de la cristallisation induite par l'écoulement d'un thermoplastique. Application à l'injection ». PhD Thesis, ENS de Cachan France 2001.

[4] A. Poitou, A Ammar, «A molecular model for flow induced crystallization of polymers » to appear in macromolecular symposia 2002.

[5] A. K. Doufas, I. S. Dairanieh, A. J. McHugh. «A continuum model for flow induced crystallization of polymer melts ». J. Rheol. 1999, 43(1):85-109. 